\title{
A integração regional como estratégia de política de Estado do Brasil na geopolítica internacional
}

\section{Sérgio Luiz Pinheiro Sant'Anna}

Doutor em Ciência Política pela Universidade Federal Fluminense, Procurador Federal, Professor da Universidade Cândido Mendes, Membro do Instituto Brasileiro de Advocacia Pública e Membro do Instituto dos Advogados Brasileiros. Presidente da Comissão de Direito da Integração e Conselheiro da Seccional da $\mathrm{OAB}$ do Rio de Janeiro, membro das respectivas Comissões de Direito Constitucional, Rio de Janeiro, Brasil

\section{Resumo}

O processo de Integração Regional se insere num movimento de articulação de países vizinhos objetivando uma maior participação no cenário geopolítico internacional. O presente artigo acadêmico se situa no campo da contra-hegemonia e defende que o Brasil deva assumir sua condição de líder regional e atuar como um player na defesa dos seus interesses e dos demais países sul-americanos, seja em virtude da participação no Mercosul, seja em virtude da participação na Unasul, junto aos demais países nos foros e espaços de discussão política como a ONU, o G-20, a OMC, dentre outros.

Palavras-chave: Integração Regional, UNASUL, MERCOSUL, Contra-Hegemonia Multilateralismo

\section{Abstract}

The process of regional integration is part of a joint motion of neighboring countries aiming at greater participation in international geopolitical scene. This academic article is in the field of counter-hegemony and argues that Brazil should assume their regional leader status and act as a player in defending their interests and other South American countries, either because of participation in Mercosur, either because of participation in UNASUR, together with other countries in the forums and spaces for political discussion as the UN, the G20, the WTO, among others.

Keywords: Regional Integration, UNASUR, MERCOSUR, CounterHegemony, Multilateralism

\section{Resumen}

El proceso de integración regional es parte de una moción conjunta de los países vecinos encaminadas a una mayor participación en el escenario geopolítico internacional. Este artículo académico es en el campo de la lucha contra la hegemonía y sostiene que Brasil debe asumir su condición de líder regional y actuar como un jugador en defensa de sus intereses y de otros 
países de América del Sur, ya sea por la participación en el Mercosur, ya sea debido a la participación en la UNASUR, junto con otros países en los foros y espacios de discusión política como la ONU, el G-20, la OMC, entre otros.

Palabras clave: la integración regional, UNASUR, MERCOSU, Contrahegemonía, El multilateralismo.

\section{I - INTRODUÇÃO}

O Estado brasileiro, mesmo em períodos governamentais de Presidentes e Partidos Políticos de correntes diversas, tem atuado numa perspectiva de ampliar a sua inserção regional nestas últimas quase três décadas, seja para busca de novos mercados e oportunidades, seja para exercer o seu papel de player que busca reconhecimento na esfera internacional.

A integração regional, desta forma, deve ser compreendida como política de Estado onde se contrapõe fatores favoráveis e desfavoráveis na busca para se atingir aos principais objetivos. A compreensão do grau de compromisso do Estado com a integração está baseada na previsão normativa do seu mais importante documento jurídico-político, ou seja, na Constituição da República Federativa do Brasil, o que permite o embasamento, no plano institucional, que legitima a atuação do Estado brasileiro na articulação das políticas integracionistas.

O surgimento do Mercosul e da Unasul se deu em conjunturas distintas, mas se caracterizou uma estratégia de aproximação entre países vizinhos no marco da conversão ao sistema democrático, com capacidade de ampliação do debate que envolve os interesses dos países da América do Sul e a clareza de que em qualquer processo de aproximação, necessariamente os Estados Unidos perdem influência no processo decisório final.

Assume relevância a posição do Estado brasileiro, pelo fato da República Federativa do Brasil ter metade da população da América do Sul (49\%); mais da metade do Produto Interno Bruto (56\%) e metade da área territorial, com os seus 8.511,965 $\mathrm{km} 2$, o que demonstra o peso político, econômico e territorial que representa a sua participação em qualquer articulação e estratégia política que venha a ser constituída na América Latina, em particular a do Sul.

O Brasil tem fronteiras com nove dos outros onze países da América do Sul, o que demonstra ser de grande interesse para a paz interna do país e da região, a manutenção de um sistema de relações amigáveis permanentes e duradouras com os seus vizinhos.

Por sua vez, o fato dos Estados Unidos não terem interesse na articulação de países vizinhos na América do Sul sem o seu controle e, em diversos momentos, orientado de forma direta ou indireta, algumas definições político-governamentais contra esta unidade de ação, sempre serve como um elemento adicional para dificultar qualquer movimento de integração entre estes países.

Levando-se em consideração que a integração é uma articulação e decisão política, cabe destacar alguns fatores favoráveis à integração, como forma de compreender os fundamentos de determinadas decisões políticas e porque algumas dessas decisões são mais rápidas e outras demandam um tempo maior de negociação e de aceitação por parte dos demais Estados.

Determinadas decisões no campo externo acabam sendo dificultadas inclusive pela falta de compreensão ou aceitação no campo interno do respectivo país, seja pela socie- 


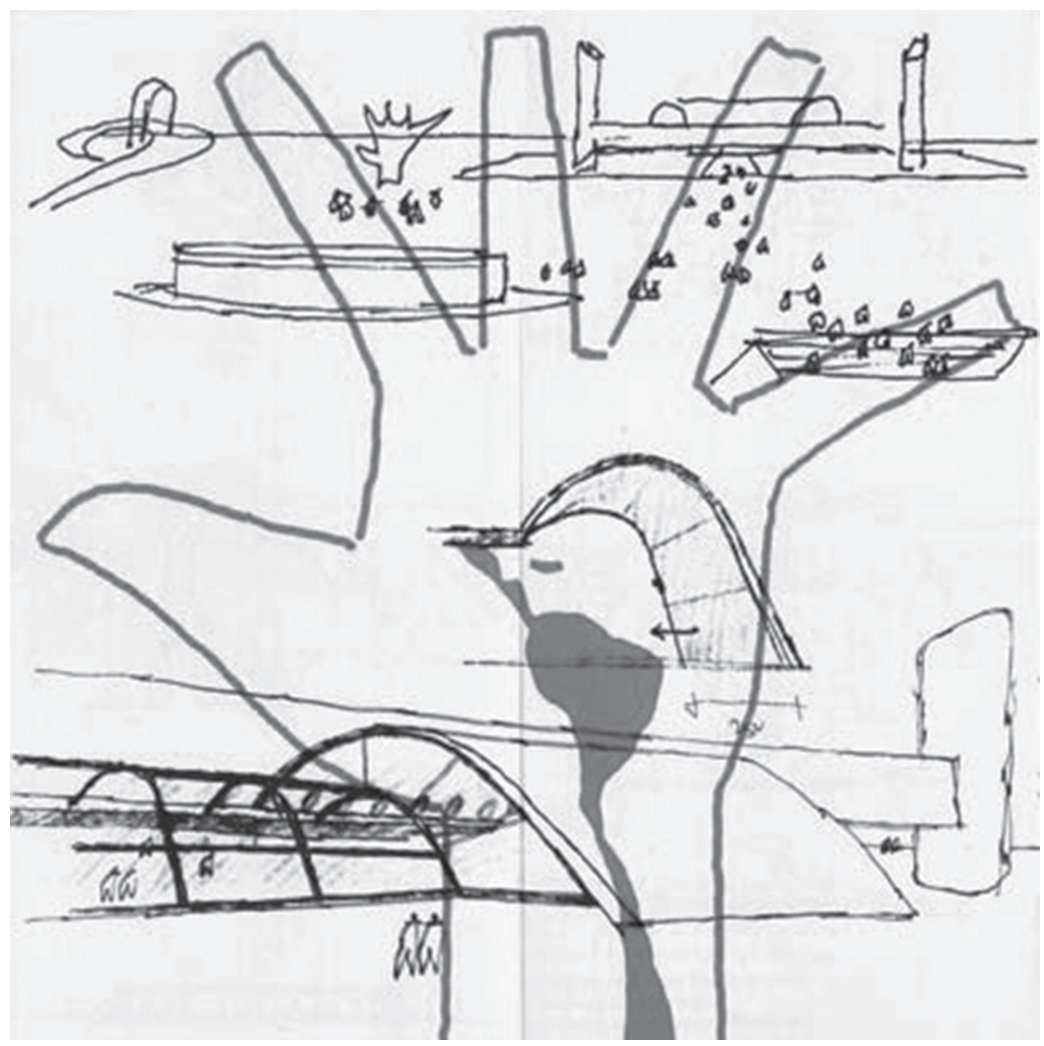

Memorial da América Latina no traço de Oscar Niemeyer,

1986. Fonte: http://memorial.org.br/

dade civil, seja pelo órgão legislativo dos Estados, seja pela pressão do empresariado local, que teme perder mercado ou escalas com decisões governamentais na esfera do bloco e, sobretudo, pressão por parte de setores da mídia que não demonstram simpatia pelos processos de integração com os países vizinhos.

Como os Estados Nacionais procuram esgotar o consenso para o processo decisório, o processo de negociação e discussão tende a ser bastante lento, em determinadas matérias, até se chegar à fase de decisão, o que pode levar a vários problemas, inclusive o de se difundir na mídia que os processos de integração não avançam e não são vantajosos para o país, o que, muitas vezes, não reflete a complexidade da matéria e os motivos pelos quais não se avançou ou se deu de forma lenta.

\section{II- FATORES FAVORÁVEIS À INTEGRAÇÃO}

Diversos fatores poderiam ser apontados como elementos que aproximam os países para uma política de integração ou de estratégias conjuntas.

Na América do Sul, a similitude histórica e política destes países pode ser apontada como fator de identificação entre estes países, sendo que neste início de século tem-se comemorado em sequência, os aniversários dos bicentenários da independência na luta contra o colonizador europeu.

O uso majoritário de somente dois idiomas, o espanhol falado em nove países e o português falado no Brasil, que detém parcela populacional significativa da América do Sul.

Outro fator de aproximação é a deficiência da infraestrutura física que dificulta o potencial de comércio regional, o que os aproxima para a implementação de ati- 
vidades conjuntas, já que todos estes países têm problemas de infraestrutura física, aprofundados por décadas de falta de investimento e na resolução de problemas microeconômicos, como inflação e desemprego.

O entendimento político dos governos em curso tem sido pela necessidade de priorização de políticas públicas conjuntas, de forma a enfrentar os grandes temas e projetos na esfera da agenda regional e mundial.

No caso do Mercosul, a criação do Fundo de Convergência Estrutural do Mercosul (FOCEM), em que o Brasil contribui com 70\%, Argentina com 27\%, Uruguai com $2 \%$ e o Paraguai com 1\%, vem sendo o instrumento que possibilita que estes países tenham maior condição de competitividade, a partir da melhoria da sua infraestrutura física, se constituindo em fator relevante e que dimensiona a necessidade de enfrentamento do problema.

A compreensão da importância da criação de organismos internacionais como no caso do Mercado Comum do Sul (MERCOSUL), Comunidade Sul-Americana de Nações (CASA), posteriormente União das Nações Sul-Americanas (UNASUL) e da Comunidade dos Estados Latino-Americanos e do Caribe (CELAC), objetiva discutir e deliberar temas de interesse destes países, sem a ingerência da posição dos Estados Unidos, principalmente, e do Canadá, o que possibilita maior autonomia decisória.

No âmbito da Unasul, a possibilidade de criação do Banco do Sul, enquanto instituição financeira que pode ter papel relevante para o desenvolvimento regional através do financiamento para obras de infraestrutura, que já vem sendo adotado no âmbito da Comunidade Andina de Nações, proporcionando assim o fomento à atividade econômica, enquanto fator indutor de desenvolvimento. No âmbito do Mercosul, a concordância do Brasil, enquanto maior parceiro comercial, com a eliminação da dupla cobrança de tarifa externa comum aos produtos de fora do bloco que entram por Paraguai e Uruguai, mas têm o Brasil como destino, além da própria formulação de um Código Aduaneiro enquanto instrumento de complementação às medidas de ordem comercial do bloco, apontam para a possibilidade de um diálogo para o avanço das instituições, de forma a permitir desdobramentos de longo prazo.

O aumento da participação e da possibilidade de acesso dos países-membros no mercado internacional, levando-se em consideração a dificuldade de complementação da Rodada Doha, no âmbito da Organização Mundial do Comércio (OMC); a crescente participação da China no comércio internacional com sua demanda por alimentos e minérios, com grandes reflexos na América Latina; a unidade para a defesa contra o crescente protecionismo de economias, notadamente Estados Unidos e União Europeia, que defendem o livre-comércio, mas não as praticam na sua plenitude; bem como, finalmente, o quadro delineado pela crise financeira internacional, iniciada em setembro de 2008 nos Estados Unidos, e que atinge em maior ou menor escala todos os países, em especial, os países desenvolvidos, que demandam estratégias conjuntas contra estas medidas, são elementos da conjuntura internacional que ampliam a possibilidade de ação coordenada e conjunta.

Outro ponto a destacar é o incremento do comércio regional, se levarmos em consideração, no âmbito do Mercosul, que no início dos anos 90 da década passada era de cerca de U\$ 15 bilhões de dólares, ao passo que em 2006 o volume era de U\$ 26 bilhões de dólares, embora questões cíclicas de ordem interna ou externa podem influenciar no ritmo de crescimento do comércio entre países. 
A criação de políticas como no caso do Programa de Substituição Competitiva de Importações (PSCI), para que o Brasil importe mais da região ao invés de outros países do mundo, desde que os vizinhos consigam competir, acaba sendo um fator de estímulo para os outros países em desenvolvimento, ao mesmo tempo que equilibra a balança comercial entre os países, para não haver situação continuada de déficit comercial ou de superávit comercial.

São apontados, ainda, como fatores que facilitam a integração: a existência de um Sistema de Solução de Controvérsias que precisa ser utilizado de forma mais efetiva; a consolidação das instituições democráticas; a necessidade de adequação das elites a um projeto mais includente e de aceitação das políticas sociais e com a efetivação dos direitos e garantias fundamentais, em particular, temas como a fome, a inclusão social, os direitos humanos, inclusão das minorias, em especial negros e indígenas e adoção de políticas públicas, que passaram a fazer parte da agenda destes países; o apoio e o compromisso de cada Estado nacional às instituições supranacionais, levando-se em consideração esta nova realidade dos múltiplos atores, principalmente num mundo multipolar.

Em que pese a dificuldade decorrente da complexidade de qualquer processo de integração envolvendo realidades de países distintos, o próprio compromisso dos governantes em apostar na integração regional, possibilita avançar na agenda e na institucionalização do bloco.

Um último aspecto a ser destacado é potencial de recursos naturais e de biodiversidade da região, o que tem facilitado contatos, reuniões e debates acerca da necessidade de proteção e inventário deste patrimônio.

No âmbito da Unasul, principalmente no Conselho de Defesa Sul-Americano, nos debates sobre os Recursos Naturais, mas também em outros foros, tem-se avançado na perspectiva da necessidade de se regulamentar o aproveitamento sustentável de todo este patrimônio natural que envolve a Amazônia, o Chaco, o Pantanal, a Patagônia, os Andes, os litorais do Oceano Atlântico e do Pacífico, os Aquíferos, enfim, a fauna, a flora e todos os recursos da região, que incluem diversos minerais estratégicos para o desenvolvimento de países e para o setor industrial e tecnológico de importantes setores da economia.

Isto possibilitará uma maior capacidade destes países em proteger e valorizar os seus produtos e ampliar as divisas financeiras oriundas de suas respectivas exportações.

Tem sido objeto de discussão, a proposta de um mapeamento das riquezas da região, particularmente aqueles recursos naturais considerados estratégicos e que tem enorme demanda por parte de países como Estados Unidos e China, para que os países da região tenham não somente uma maior capacidade de negociação de suas commodities, com preços compatíveis com a importância do recurso natural, mas também possam ter condições efetivas de proteção no âmbito governamental, inclusive no plano legiferante interno e administrativo, como patentear os seus produtos nativos, protegendo-os da biopirataria.

\section{III- 0 SIGNIFICADO DA INTEGRAÇÃOO}

O significado do processo de integração, ao longo destas décadas, permite compreender os fundamentos que estimulam o intercâmbio entre os países na conjuntura atual, na qual existem elementos de ideologia, de base no Comunitarismo, na Solidariedade 
e no respeito entre os povos, aliados ao pragmatismo e visão mais próxima da análise de conjuntura, que levam à possibilidade de países de forma conjunta, poderem se constituir em atores com maior capacidade de interlocução global.

Os processos de integração tendem a ser influenciados pela visão econômico-comercial, por parte da atuação do empresariado e da representação do fator capital, na defesa e na ampliação dos seus interesses que acabam convergindo com os interesses do Governo, na medida em que ampliação de escalas produtivas, superávit na balança de pagamentos e aumento das exportações são políticas de interesse dos Estados para efetivar o crescimento econômico e o estímulo às políticas públicas internas, com a geração de emprego e renda.

Existe um aspecto significativo do processo de integração ao longo deste início de século XXI, que foi a capacidade dos países da América do Sul, em grau de intensidade diferenciado evidentemente, mas dentro da lógica da integração, em compreender que integração não pode se limitar a atividade de comércio e na busca de indicadores econômicos, sem um projeto social, político e cultural que possibilite avançar no que seria a real dimensão de uma integração.

Qualquer desenho e formulação de medidas integracionistas é, antes de mais nada, política e deve ter conexão com um modelo de Estado que consiga aliar a orientação política às questões econômicas, sociais e culturais, objetivando estabelecer um projeto mais amplo de integração, embora seja natural a busca pelo avanço comercial.

Verifica-se que os dois processos de integração em curso estudados ao longo deste artigo, o Mercosul e a Unasul, têm se pautado na perspectiva da legitimação dos canais decisórios, principalmente a partir da primeira década do terceiro milênio, mesmo com naturais dificuldades típicas de processos de integração com atores bastante diversificados e assimétricos, desde o fator econômico até o fator territorial, passando pelo populacional.

$\mathrm{Na}$ esfera do comércio, o desequilíbrio cambial entre o Brasil e os principais mercados China e Estados Unidos, acaba afetando o saldo comercial do Brasil com a América do Sul e a União Europeia, segundo diagnóstico elaborado em pesquisa da Federação das Câmaras de Comércio e Indústria da América do Sul (Federasur), já que a pauta de exportações do Brasil é baseada em produtos primários, destacando-se minérios, soja em grãos, petróleo e derivados, entre outras commodities, que, inclusive, dominam a relação dos 15 (quinze) principais produtos.

No campo das importações destacam-se peças e componentes de itens de maior valor agregado como peças para a indústria eletrônica, o que vem provocando debates no Brasil, que se estende pela América do Sul, sobre o processo de desindustrialização.

Mesmo com todos os problemas do pós-crise de 2008, a corrente de comércio com os países vizinhos sul-americanos cresceu $41 \%$ no $1^{\circ}$ bimestre de 2012 , com a redução do superávit comercial na ordem de $-26 \%$, o que demonstra maior equilíbrio nas relações comerciais.

De 2009 para 2010, o peso da região no âmbito do comércio brasileiro saiu de $14,94 \%$ para $16,91 \%$, sendo que entre janeiro a dezembro de 2009 , o saldo comercial entre Brasil e a América do Sul foi favorável na ordem de $\mathrm{R} \$ 7.929 .014,00$ (sete milhões, novecentos e vinte e nove mil e quatorze reais) e a corrente de comércio movimentou $\mathrm{R} \$ 46.087 .095,00$ (quarenta e seis milhões, oitenta e sete mil e noventa e cinco centavos), valores em reais. 


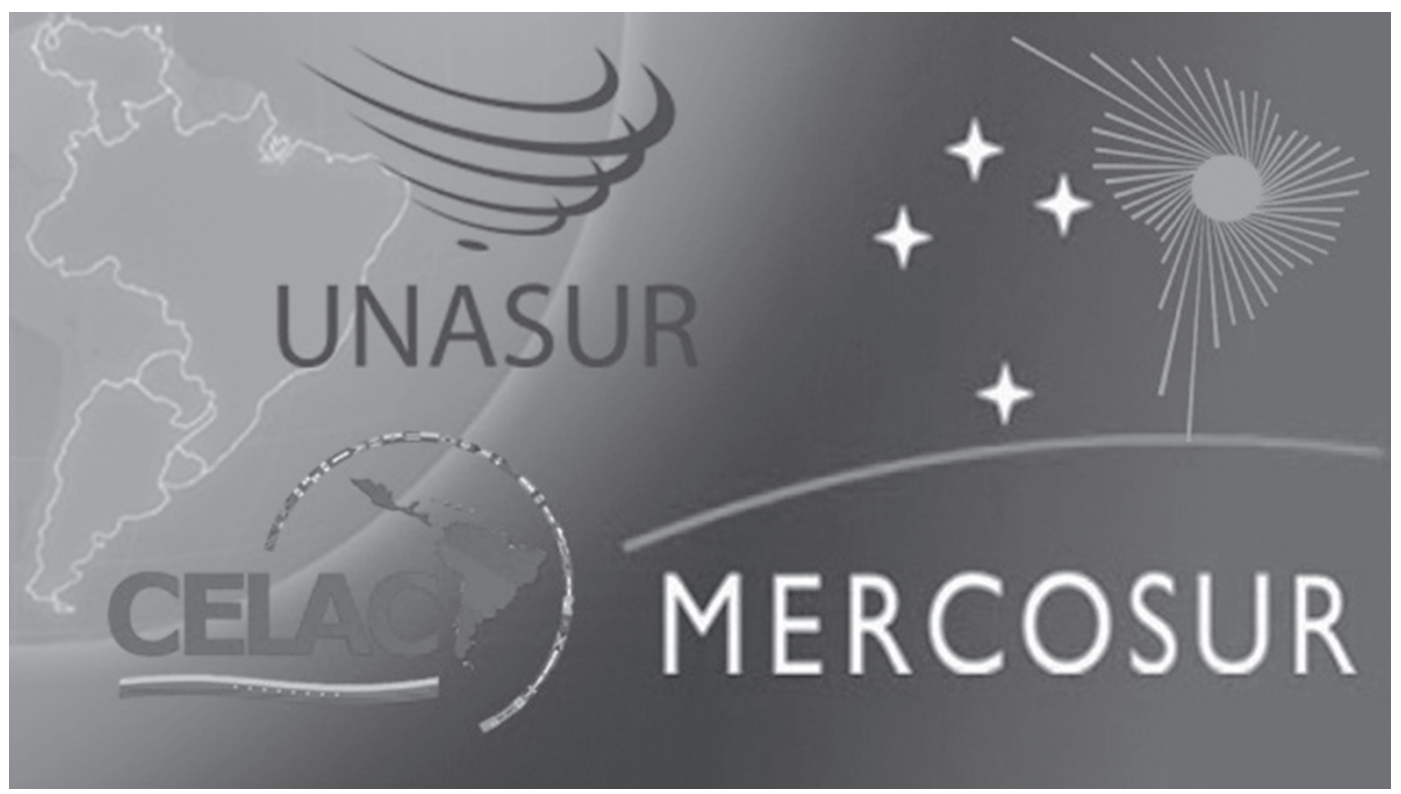

Fonte:http://jornalggn.com.br/

Em 2008, a China tornou-se o principal parceiro comercial brasileiro, sendo que as exportações do agronegócio para esse pais somaram U\$ 8,9 bilhões em 2009, o que correspondeu ao equivalente a quase $14 \%$ dos embarques agropecuários nacionais. $\mathrm{O}$ principal produto exportado foi o complexo de soja, na ordem de U\$6,75 bilhões.

O fator China é um componente de grande relevância para a região porque possibilita um equilíbrio e, ao mesmo tempo, um contraponto ao poder dos Estados Unidos da América, de forte tradição de intervenção e influência geopolítica na região.

O problema inverso é a quantidade de produtos que são enviados pela China para o mercado dos países da América Latina e Caribe, em especial os da América do Sul, alguns deles com baixo padrão de qualidade, e que acabam competindo com os próprios produtos da região em condições favoráveis.

Registra-se que a China tem investido em ciência, tecnologia, inovação, capacitação da sua mão de obra e na qualificação dos seus produtos, tentando aperfeiçoar e diversificar a sua produção industrial, além da melhor qualidade dos seus produtos exportados para os outros continentes.

Neste contexto, o peso da influência da China tem que ser pensado no curso do processo de integração, de forma a possibilitar o estabelecimento de políticas e medidas de curto, médio e longo prazo para a defesa dos produtos e dos mercados da região, que vem sendo inundado de produtos oriundos daquele país, em algumas situações caracterizando-se a prática de dumping e da concorrência desleal entre mercadorias internas.

Se o avanço do processo democrático e a atual convergência de orientação política dos governos e dos fundamentos ideológicos em campos políticos próximos na maioria dos países sul americanos, vem facilitando acordos e estratégias de atuação conjunta, questões relevantes suscitam controvérsias que precisam ser debatidas e superadas.

No âmbito militar, a ampliação do acordo de cooperação entre a Colômbia e os Estados Unidos para combate às Forças Armadas Revolucionárias da Colômbia (FARC), é um fator de permanente instabilidade e preocupação para toda a região, até pelos antecedentes da atuação estadunidense que contribuíram para os regimes militares em diversos países. 
A perspectiva de uma solução negociada e pacífica é sempre a melhor maneira de resolver o conflito, indo na posição contrária aos interesses estadunidenses que preferem a extensão destas bases militares, principalmente em razão do inimigo invisível do terrorismo, declarando a região da Tríplice Fronteira, localizada entre Brasil, Paraguai e Argentina como uma região de potencial foco de ingresso de terroristas no continente.

Mesmo tendo o Equador e o Peru, nesse caso a partir da eleição de Ollanta Humala, declarado que não manteriam bases americanas em seus respectivos países, os Estados Unidos continuam utilizando instrumentos de pressão para continuar mantendo a sua hegemonia e o seu controle no continente.

No âmbito econômico-comercial, os acordos de livre-comércio bilaterais que os Estados Unidos têm tentado implementar com determinados países, sob o ponto de vista principalmente do Mercosul, constitui-se em fator de desestabilização, pois existe proposta de ampliação do Mercosul que choca-se com este projeto bilateral de comércio.

A quantidade de pessoas que saiu da linha de pobreza no último decênio é significativa, mas a situação ainda é complexa e exige políticas públicas, baseadas num planejamento articulado para reversão de um problema histórico de décadas.

Os reflexos da crise mundial nas respectivas economias, que vem sendo debatido no âmbito da Unasul de forma mais intensa, vem demonstrando a necessidade de aprofundamento de temas de interesse de todos os países, como a priorização de projetos de infraestrutura; as divergências na comercialização entre mercadorias de países vizinhos, como a recente agenda de reuniões para discussão de problemas entre Argentina e Brasil, sob o argumento de proteção da indústria interna; e a diminuição das assimetrias entre os países, que vem norteando os debates no âmbito do Mercosul.

Pela dimensão que adquiriram os processos de integração na América do Sul, em particular o Mercosul e a Unasul, deve-se buscar uma visão mais política da integração no paradigma da contra-hegemonia, o que deve ser uma análise de fundamento político, já que se fosse para manter uma integração hegemônica, teríamos somente a preponderância da atividade comercial.

\section{IV - CONCLUSÃO}

Processos de integração como o Mercosul, a partir do segundo decênio, e a Unasul refletem o estágio em que a América do Sul tem se movimentado no contexto geopolítico atual e no que tange as fases da Globalização do início deste século.

A Globalização deve ser entendida como um conceito em construção, dialético e que corresponde a uma realidade empírica, onde estudiosos das Ciências Sociais e das Ciências Econômicas convergem ao estabelecer uma relação de associação às mudanças significativas que vêm ocorrendo nas relações políticas, econômicas, sociais e culturais do mundo contemporâneo.

A globalização retrata o mundo vitorioso da Segunda Grande Guerra baseado numa estrutura institucional do sistema mundial totalmente calcada na hegemonia estadunidense através de instituições como o Banco Mundial, Fundo Monetário Internacional, Acordo Geral de Tarifas e Comércio (GATT), atualmente Organização Mundial do Comércio (OMC), além do desenho estrutural da Organização das Nações Unidas concebida no quadro desta hegemonia e que respeita o interesse das forças aliadas na 
Segunda Guerra Mundial traduzida pelo poder de veto dos Estados Unidos, da então União das Repúblicas Socialistas Soviéticas, atualmente Rússia, França, Reino Unido e China junto ao Conselho de Segurança da Organização das Nações Unidas, mas a partir da década de noventa do século anterior se viu impulsionada por um cenário político internacional que não mais encontrava os obstáculos da Guerra Fria, aliado a um cenário que retrata o enorme avanço tecnológico da informática, dos meios de comunicação e da informação, com maior facilidade de deslocamento dos fluxos de capitais e as relações entre os países.

O processo de globalização passou a ter a visão unipolar com a ascendência americana da visão neoliberal e da doutrina preconizada pelo Consenso Econômico Neoliberal, baseada no pensamento único que durou por pouco menos de duas décadas, na medida em que o modelo preconizado por esta concepção política e econômica se mostrou falho e totalmente contrário a um processo de recuperação com soluções adequadas aos países que aplicaram o seu receituário.

$\mathrm{O}$ atual processo de globalização se pauta numa Hegemonia Compartilhada, a partir de uma visão multilateral que propicia que os Estados Unidos, em maior escala, e a Europa integrada e o Japão, em menor escala, terão menor poder de persuasão na medida em que verificam a ascensão de outras potências que se constituem em novas economias industriais e lideranças no âmbito regional, como a China, a Índia, o Brasil, o México, a Turquia, a África do Sul, países asiáticos, além do ainda considerável poder de influência da Rússia.

O multilateralismo tem propiciado que os países possam ter uma maior participação no processo de influência de grandes temas na agenda internacional, não somente por beneficiar-se do sistema do regionalismo aberto, mas também pela sua articulação em processos de integração regional.

O Regionalismo aberto consiste num complexo processo onde os países envolvidos tratam da liberalização do comércio de bens e serviços entre os membros do modelo de integração, mas sem aumentar as barreiras de tal comércio frente a terceiros países, dentro dos compromissos jurídicos adquiridos por força da Organização Mundial do Comércio. Em outras palavras, representa um processo de integração regional que intensifica a crescente interdependência econômica que pode avançar em aspectos políticos, sociais e culturais.

A Organização Mundial do Comércio (OMC) admite duas interpretações para o conceito de regionalismo aberto. $\mathrm{Na}$ primeira é considerado como assegurada a consistência dos acordos regionais com o sistema multilateral, cuja natureza estaria ameaçada pela proliferação de grupamentos regionais, transformando em regra a exceção ao princípio da nação mais favorecida. Alguns autores entendem que chegaríamos em 20 anos, a uma divisão do comércio mundial em 2 ou 3 blocos intercontinentais, cada um com suas regras e livre-comércio intrabloco, mas as barreiras entre os blocos continuaria a existir. Na segunda interpretação, considera-se que as barreiras internas ao comércio, no âmbito de uma determinada região seriam gradualmente eliminadas mais ou menos à mesma taxa e na mesma cadência de redução das barreiras em relação aos países não membros. Esse seria um caso ideal, mas utópico, onde haveria uma convergência gradual do regionalismo para o multilateralismo sem protecionismo e práticas discriminatórias, já que o princípio de nação mais favorecida seria preservado.

No início do século XXI a liberalização do comércio se intensificou e passou pelos caminhos do multilateralismo e o bilateralismo. Sobre o multilateralismo, um 
dos principais exemplos é o papel desempenhado pelos países nas discussões sobre a agricultura durante a Rodada Uruguai do GATT (1986-1993) pela sua amplitude, principalmente no que tange às questões agrícolas.

A regionalização tem implicado num processo de multiplicação dos tratados de integração regional em todo o mundo. O Brasil tem se caracterizado por exercer a sua hegemonia não em termos tradicionais, baseada na ação armada, expansionista ou na dominação política, mas sim o de buscar o reconhecimento de sua liderança regional, e com isto ampliar o seu poder político no plano internacional se inserindo como um global player.

Esta inserção estratégia internacional do Brasil passa pelo fortalecimento do processo de integração regional sul-americano e tem como pilares fundamentais a delimitação desta região como área de sua influência através dessa integração regional, sem prejuízo de uma política multilateral de adesão e participação das instituições e acordos internacionais, como forma de aumentar a sua influência, mas também a manutenção da estabilidade regional.

Em síntese, depreende-se que o regionalismo e o multilateralismo complementam-se no sentido de se definir uma política externa "universalista" e que rejeita o alinhamento automático aos Estados Unidos e busca afirmar o exercício de sua hegemonia no plano regional, priorizando a sua ação política na América do Sul, através dos laços históricos e de similitude.

Com base nos pressupostos explicitados, os processos regionais sul-americanos, embora reconhecendo as naturais dificuldades e desacertos, tem buscado criar sua própria identidade, valores e procedimentos, com o objetivo de estabelecer metas e diretrizes conjuntas para uma maior inserção no cenário global.

A integração regional vem se consolidando, através de políticas e estratégias debatidas pelos Chefes de Estado e de Governo junto às instâncias institucionais, que foram criadas para que a efetividade do processo decisório se traduza em ações no campo político e diplomático, com reflexo nas áreas sociais, econômicas e culturais, inclusive mediante regulamentação jurídica.

Finalmente, a ação política favorável ao processo de integração regional deve se inserir no campo da contra-hegemonia e de repúdio ao modelo neoliberal e à lógica do Estado em função dos interesses da Empresa e dos mercados.

\section{V- REFERÊNCIA BIBLIOGRÁFICA}

BARROS, Sebastião do Rego. Mercosul: Tempos de Desafio. In: REVISTA LATINOAMERICANA de Temas Internacionais. Archivos Del Presente. Buenos Aires, Fundación Foro Del Sur, 2000, n. 19.

BATISTA JÚNIOR, Paulo Nogueira. Brasil, Argentina e América do Sul. Estudos Avançados. São Paulo, vol. 19, n. 55, set/dez, 2005.

CANÇADO TRINDADE, A. A., Regionalismo abierto en América Latina y el Caribe. La integración económica en servicio de la transformación productiva con equidad. 1994.a. Disponível na Internet: www.eclac.org/espanol/textosfund/Cepal6.html GAMBINA, Júlio. Las crisis de la economía mundial y los desafíos para el pensamiento crítico

GUIMARÃES, Samuel Pinheiro. O papel politico internacional do Mercosul. In: 
LAVAGNA, Roberto. Alianzas Regionales: Mercosur, Nafta y la Unión Latinoamericana. Argentina y Brasil en el Mercosur. Grupo Editor Latinoamericano, 1995.

SADER, Emir. Democracia sin exclusiones ni excluidos. Caracas/Venezuela: Nueva Sociedad, 1998.

SANTOS, Theotonio (Coord.) Economia Mundial, Integração Regional e Desenvolvimento Sustentável - As Novas Tendências da Economia Mundial e a Integração Latino-Americana, Petrópolis: Editora Vozes, 1993.

Fonte: www.mre.gov.br (sítio do Ministério das Relações Exteriores) 